\title{
A Case Report of Facial Bite Marks; Reference of Methods of Analysis
}

\author{
${ }^{1} \mathrm{C}$. Stavrianos, ${ }^{1} \mathrm{~L}$. Vasiliadis, ${ }^{2} \mathrm{C}$. Papadopoulos, \\ ${ }^{1}$ A. Pantazis, ${ }^{1}$ N. Petalotis, ${ }^{1}$ D. Tatsis and ${ }^{1}$ E. Samara \\ ${ }^{1}$ Department of Endodology (Forensic Odontology), \\ School of Dentistry, Aristotle University, Thessaloniki, Greece \\ ${ }^{2}$ Department of Forensic Sciences (Forensic Odontology), University of Glamorgan, Wales
}

\begin{abstract}
The trauma caused on the skin from the contact of the teeth with or without the contribution of the soft oral tissues (lips, tongue) is defined as a bite mark. They can be caused either by humans or by animals and are usually found in two kinds of cases: crimes and homicides with and without sexual activity and child abuse. Bite marks can be found on both victims and assaulters. In mortal combat situations such as the violence associated with life and death struggles between assailants and victims, the teeth are often used as a weapon. Indeed using the teeth to inflict serious injury on an attacker may be the only available defensive method for a victim. The frequency of occurrence of bite injuries at specific locations varies with the type of crime and sex and age of the victim. This case report aims to present a victim who was involved in a fight and the facial bite mark on the right part of the face was the only evidence for that. The concurrent methodology on collecting data from the mark and the possible suspect as well as the comparison techniques is also reported.
\end{abstract}

Key words: Facial bite mark, types of bite marks, methods of analysis, comparison techniques, death, Greece

\section{INTRODUCTION}

Forensic dentistry is the branch of dentistry that deals with the legal aspects of professional dental practices and treatment with particular emphasis on the use of dental records to identify victims of crimes or accidents. One sector of forensic odontology is the analysis of bite marks. According to the American Board of Forensic Odontology, the human cutaneous bite mark is defined as follows: An injury in skin caused by contacting teeth (with or without the lips or tongue) which shows the representational pattern of the oral structures (ABFO, 2000).

Bite wounds are one of the most frequent human traumas (ABFO, 2000; Stavrianos and Vasiliadis, 2002; Stefanopoulos and Tarantzopoulou, 2005; Stavrianos et al., $2011 \mathrm{a}, \mathrm{b}$ ). The bite mark can be caused either by human or by animals. Bite marks are usually seen in cases involving sexual assault, murder, child abuse and can be a major factor in leading to a conviction. Bites are often located on breasts, inner thighs, arms buttocks and genitalia. Bites on the back are common findings in both male and female victims (Vale and Noguchi, 1983). Many violent assaults consist of more than one bite, making some bites difficult to identify. Bite marks will appear as a circular or oval patterned injury consisting of two opposing symmetrical, U-shaped arches separated at their bases by open spaces. Many variations are observed including partial bites where only one arch or side is observed (an artifact caused by biting through clothing) and avulsion where part of the tissue has been torn away. Injuries observed with bite marks include abrasions, lacerations, contusions/bruises, petechiae, indentations, erythema and punctures (Jones, 1998; Bell, 2000; ABFO, 2000; Webb et al., 2000; Bowers, 2006).

\section{TYPES OF BITE MARKS}

A representative human bite is described as an elliptical or circular injury that records the specific characteristics of the teeth. The injury may be shaped like a doughnut with characteristics recorded around the perimeter of the mark. Alternatively, it may be composed of two U-shaped arches that are separated at their bases by an open space. The diameter of the injury typically ranges from $25-40 \mathrm{~mm}$. Often a central area of bruising can be seen within the marks from the teeth. This extra vascular bleeding is caused by pressure from the teeth as they compress the tissue inward from the perimeter of the mark (Rothwell, 1994). We can identify these types of bite marks:

Corresponding Author: Christos Stavrianos, Department of Endodology (Forensic Odontology), School of Dentistry, Aristotle University, Thessaloniki, Greece 
- Hemorrhage-small bleeding spot

- Abrasion-undamaging mark on skin

- Contusion-ruptured blood vessel, bruise

- Laceration-punctured or torn skin

- Incision-neat puncture of skin

- Avulsion-removal of skin

- Artifact-bitten-off piece of body

These types can be classified by four degrees of impression:

- Clearly defined-significant pressure

- Obviously defined-first degree pressure

- Quite noticeable-violent pressure

- Lacerated-skin violently torn from body

The marks left by the teeth in a person may be used to identify an individual. The characteristics of human bites are superficial abrasion and/or sub-surface hemorrhage looking like an arch. They are caused by the incisors canines and premolars. The abrasions and/or hemorrhage caused by the canine are in a shape of points. Contusions are the most common type of bite mark and incisions offer the best three-dimensional image of the teeth. It can also be determined from the type of bleeding beneath the skin whether the victim was alive or dead at the time the bite mark was delivered (Cottone and Standish, 1982; Rothwell, 1994; ABFO, 1995).

\section{HISTORICAL TRENDS}

It was the 1870 when the first conviction based on bite marks took place as evidence was in the case of Doyle v. State which occurred in Texas in 1954. In order to make a comparison, the defendant bit another piece of cheese which was examined by a firearms examiner and a dentist who made an independent evaluation of the bite marks and both reached to the conclusion that it was the same set of teeth. This case set the base for bite marks found on objects and skin to be considered evidence in future case (Bowers, 2006). In 1971 DeVore ink models to place marks on living volunteers and cadavers. The bite marks were photographed in several body positions and skin bearing the ink was removed. Apparently, there is little possibility of error making use of bite marks photographs and the unsecured tissue sample (De Vore, 1971). People v. Marx was another landmark case in California in 1975 during which a woman was strangled after sexual assault and several hits on her nose. Three experts testified that the bite marks on the woman's nose were caused by Marx. Walter after the examination of the dental impressions of the attacker's teeth. Impressions and photographs were also taken of the woman's nose. A variety of techniques including: two dimensional and tree-dimensional comparisons and acetate overlays in order to examine and evaluate the samples along with other models and casts. After this procedure, the three experts testified against Walter Marx who was convicted of voluntary manslaughter (Dorion, 2005). McKenna et al. (1999) reported a case in which the identification of the attacker was made by comparing the bite marks inflected on the avulsed portion of the victim's ear with the translucent acrylic replica made from the assailant dental impression. In 1984, the ABFO gave the first bite-mark analysis instructions. This analysis includes the documentation of the description concerning the bite marks, the collection of evidence from the victim, collection of evidence from the attacker and analysis of the information. The guidelines were revised and redistributed in 2000 (ABFO, 2000). The examination of either a whole or partial set of teeth by experts helps them to identify patterns. Experts examine the nature of the bite mark whether the bite is human or animal; they record the size, its appearance, color and location of the bite on the cadaver as well as the number of other bites on the body. It is also essential for the examiners the determination of washing, contamination, lividity, embalming, decomposition, change of position, etc. and their effect on the bite mark.

\section{CASE REPORT}

In this study a case of a facial bite mark is reported. The victim in this case was involved in a fight and the facial bite mark on the right part of the face was the only evidence for that. The victim was referred to the hospital for care. The aggressive bite mark shows the involvement of this man to a fight. The photograph shows clearly the injury-bite mark occurred by the cutting edges of the attacker to the victim's face (Fig. 1). In this incidence no metric photographing was made with the use of millimeter scale A.B.F.O. $\mathrm{N}^{\circ} 2$ that is imposed by the Forensic dentistry so that the evaluation of the natural size of the traumatic damages is possible. If this scale is not available, a ruler or an object of a consistent known size such as a coin could be used.

As far as the antibiotic prophylaxis is concerned, antibiotics are not generally needed for wounds $>2$ days old if there is no sign of infection. Usually, antibiotics are considered for bites involving hands, feet, ligaments, tendons, fractures or for penetrating bites in people with poor immunity, diabetes or cirrhosis. In this certain patient, Co-amoxiclav (amoxicillin/clavulanic acid $500 / 125 \mathrm{mg} \mathrm{tds}^{-1}$ for adults and $40 \mathrm{mg} \mathrm{kg}^{-1}$ tds doses 


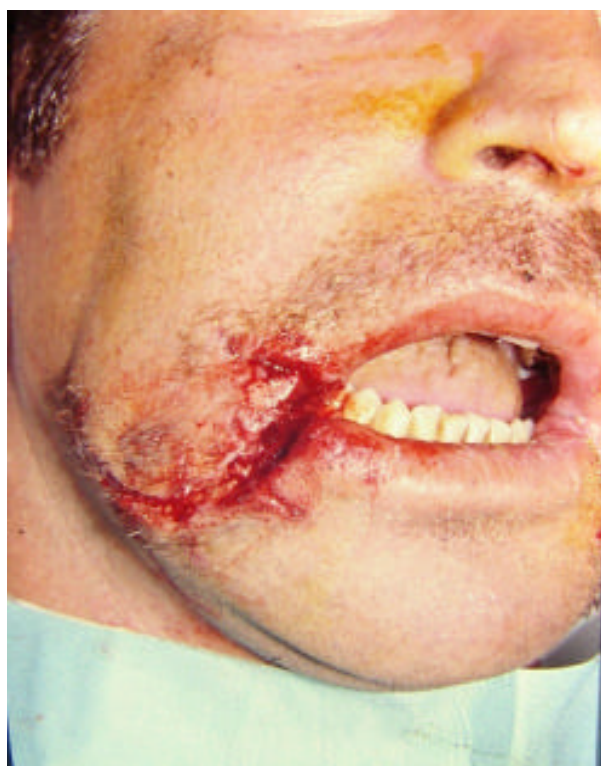

Fig. 1: The injury bite mark on the right part of the victim's face

based on amoxycillin for children) would be given for 5-7 days. The patient was allergic to penicillin, so it was prescribed doxycycline $\left(100 \mathrm{mg} \mathrm{bd}^{-1}\right)$ and metronidazole $\left(500 \mathrm{mg} \mathrm{tds}^{-1}\right)$ for those over 12 or erythromycin and metronidazole for those $<12$ years old. The wound was obviously infected so antibiotics were given for 10-14 days. Also, treatment for tetanus was prescribed for precaution reasons.

\section{METHODS OF ANALYSIS}

According to the diplomats of the A.B.F.O the methods that are used are the following:

\section{Bite site evidence}

Saliva swabs of bite site: The aim of swabbing the bite site is now solely the collection of cells for DNA. It has been shown that this trace evidence is present in sufficient quality and quality to enable PCR-based typing of the DNA that is present in saliva from white blood cells and possibly from sloughed epithelial cells (Sweet et al., 1997a). If the DNA profile obtained from the bite mark matches the DNA profile of the suspect there only two possible explanations for how this might happen. Either the suspect is the depositor or someone else possessing the identical DNA profile deposited the saliva. To evaluate the likelihood of this second scenario, calculations are completed to evaluate how rare or common the profile is in the general population. The double swab method will maximize the amount of DNA recovered (Shoemaker et al., 1999).
Photographic documentation of the bite site: The bite site should be photographed using digital and/or conventional photography. Photographic resolution should be of high quality (right color, light and angle, etc.). Orientation and close-up photographs should be taken. Photographs of the mark should be taken with and without a scale (A.B.F.O) in place. Video imaging may be used in addition to conventional and digital photography (Kraus, 1984; Hyzer and Krauss, 1988; Wright and Golden, 1997). To photograph bite-mark injuries, the camera should be positioned at a $90^{\circ}$ angle to the bite. If the bite is on a curved surface, separate photographs of the arches will need to be taken so that both are at $90^{\circ}$ (Sperber and Lubin, 1981).

Impressions: Impressions should be taken of the surface of the bite mark whenever it appears this may provide useful information. The dentist has access to a variety of materials in which to choose the right gum, rubber plastic powder to make a cast. When a self-inflicted bite is possible impression of the individual's teeth should be made (ABFO, 1995; Sweet, 1995).

Tissue samples: In the deceased, tissue specimens of the bite mark should be retained whenever it appears this may provide useful information. The bite may be excised and preserved following proper stabilization prior to removal with appropriate approval. Some forensic dentists use the Dorion method which advocates the removal of bitten tissue for microscope examination (Dorion, 2005).

Summary of the methodology: The outlined procedures ensure that forensically significant evidence is secured by the best possible means of they are strictly followed. All the exhibits will enable the odontologist to make comparisons with known data from suspects in order to identify or eliminate those (Sweet et al., 1997a).

\section{EVIDENCE COLLECTION OF SUSPECTED DENTITION}

Before collecting evidence of the suspect the odontologist should ascertain legal permission.

Dental records of suspect (Sweet, 1995): Whenever possible the dental records of the individual should be obtained in accordance with the ABFO Bitemark Analysis Guidelines.

History: A continued dental history of the suspect should be charted given the possibility that he or she may attempt to change their bite profile. 
Photography: Photographs should be taken with full face profile, intraoral and extraoral. Video imaging may be used to document the dentition in addition to conventional or/and digital photography (Wright and Golden, 1997).

Extraoral examination: The extraoral examination should include observation and recording of significant soft and hard tissue factors and measurement of maximal opening of the mouth noting any deviations in opening or closing (Pretty, 2000).

Intraoral examination: Special attention is focused on the status of the general dental health, occlusion and mandibular articulation. Some evidence of the intraoral examination could be periodontal pocketing, diastemata, restoration etc. (Pretty, 2000; Pretty and Sweet, 2001).

Impressions: Whenever feasible at least two impressions should be taken of each arch. The interocclusal relationship should be recorded (Sweet, 1995).

Sample bites: Sample bites from the suspect should be made into an appropriate material stimulating the type of bite under study (Sweet, 1995).

\section{Study casts (Sweet, 1995)}

Saliva samples: A saliva sample is taken for DNA testing. DNA evidence can be obtained by swabbing the area of the bite. Many programs are now using a method that requires use of a double-swab technique developed by Dr. David Sweet and colleagues. According to Dr. Sweet, the first swab rehydrates and loosens the majority of the epithelial cells and when the second dry swab is applied, the cells in the saliva are able to adhere to the fibers more easily. One swab is collected by moistening it with one drop of sterile water and rolling it across the area of the bite. A second dry swab is then rolled across the same area. Both swabs are then air dried, placed in an envelope, sealed and labeled with the victim's name, date and time collected, location from which it was collected and who collected it. This same technique should be used when collecting saliva evidence from areas that may have been licked, kissed or sucked on (Sweet, 1995; Sweet et al., 1997a, b; Sweet and Shutler, 1999). The physical characteristics of both the bite mark wound and the suspect's teeth include: The distance from cuspid to cuspid the shape of the mouth arch and the evidence of a tooth out of alignment in a national database.

Summary of the methodology: These procedures are tolerated by most subjects although, it is recommended to collect the most significant exemplars such as photographs and study models, early in the examination in case the suspects becomes uncooperative. Once all the exhibits are collected, the comparative analysis can determine a possible identification (Sweet et al., 1997a).

\section{METHODS OF COMPARING EXEMPLARS TO BITE MARKS}

The most common methods to determine if the suspect's teeth caused the bitemark include techniques to compare the pattern of the teeth (shape, size, position of teeth, individually and collectively) with similar traits and characteristics present in life-sized photographs of the injury using transparent overlays. These overlays have been produced using various techniques (Sweet and Bowers, 1998). The most accurate technique has been found to be a method using a computer (Fig. 2 and 3), (Sweet et al., 1998; Stavrianos et al., 2003, 2011a, b).

Computer-assisted technology can be utilized for bite mark evaluation both on skin and inanimate objects (Fig. 3) and lately as a tool for the production of comparison overlays; the entire operation may be performed on the desktop giving faster, better and more reliable results compared to the previously used techniques as long as it relies on non-distorted photographs of the injury (Nambiar et al., 1995; Pretty, 2006; Stavrianos et al., 2011a, b). Other methods employed for analysis by A.B.F.O. are: transillumination of tissue, computer enhancement and/or digitization of mark and/or teeth, stereomicroscopy and/or macroscopy, scanning electron microscopy, video superimposition,

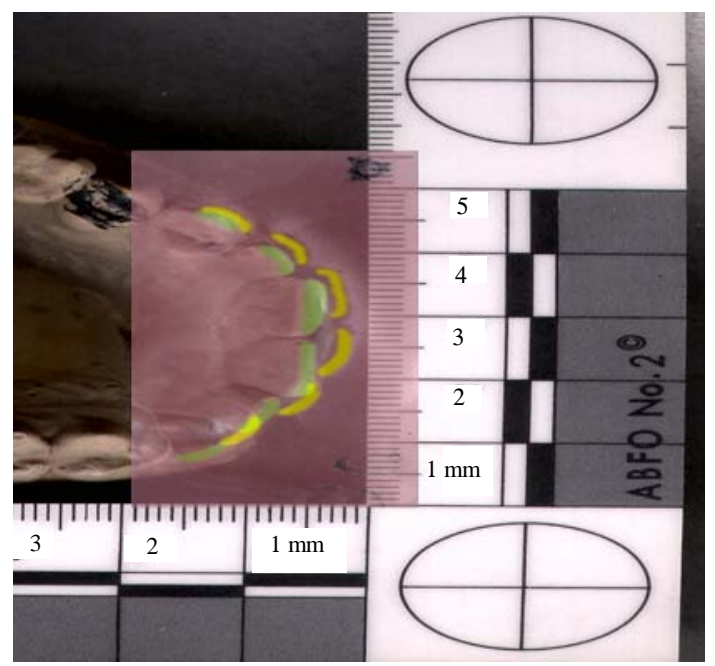

Fig. 2: Comparison of the upper dentition of suspect with the bite mark pattern using the computer assisted overlay production technique with Adobe Photoshop CS4 software (indirect method) 


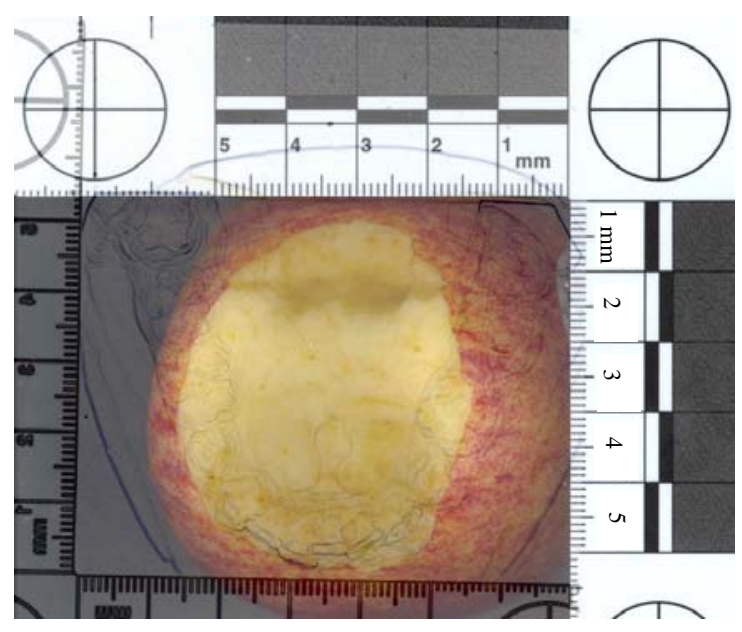

Fig. 3: Comparison of the lower dentition of suspect with the bite mark pattern (found in foodstuff) using the Adobe Photoshop CS4 software

histology (ABFO, 2000; Herschaft et al., 2006; Rawson et al., 1979; David, 1986). Some effort has been made to standardize the comparison procedures but unfortunately, the conclusions are often based on the expert's level of personal experience and judgement (Rothwell, 1995). The American Board of Forensic Odontology has worked hard to establish guidelines for independent examination of the same evidence by second and third odontologists before the primary expert submits a final report. Regardless, many cases have been disputed because of differing expert opinions, attacks on the scientific basis of physical comparisons because of the elasticity of skin and the question of uniqueness of the human dentition (Pretty, 2000; Herschaft et al., 2006).

\section{DISCUSSION}

Bite marks are usually a result of violent interpersonal conflicts induced by child or elder abuse, sexual assault or homicide. Human bite marks tend to differ from person to person and from physical attack to another. The bruises that occur from the bite mark have a huge variety of characteristics such as the healing process which alternates the colour according to the phase, the incomplete teeth marks without 3-D features and the surface bitten which does not register physical indentations accurately. Movement during the bite usually alternates the physical features of the mark, resulting to lack of identification. The autopsy and analysis of a bite mark follows a logic tree of questions during the investigation including whether the pattern is a bite mark if it is caused by human or animal if it is by a child or adult if it is self-inflicted and whether it is identifiable. The last and rather important question is whether the teeth marks present have enough unique characteristics to be attributable to one particular perpetrator (Sweet and LeRoy, 1996, Herschaft et al., 2006). Bite marks from a single jaw (single-arched) almost always tend to give inadequate information in order to positively identify the possible suspect. In cases of interposed clothing, dull surfaces of teeth, variations in skin and skin support, more rapid fading of one arch (usual the upper), the final result is obviously faded and indistinct mark with less possibility of identification. This is a result of collective pressure of teeth within an arch leaving a continuous curved contusion, especially in soft yielding skin (children, women) and in the procedure of healing process (Cottone and Standish, 1982; ABFO, 2000). Due to the rapid change of clarity and size of the bite injury both in living bodies and dead bodies, the identification of the injury should be done as quickly as possible since a large proportion of individuals (about $80 \%$ ). Secrete AB blood group in their saliva, swabbing the bite site is an essential prerequisite. The swab (together with a control swab from elsewhere on body) should be moistened with sterile distilled water, air dried and submitted to a serological or forensic laboratory (Johnson and Cadle, 1989). The fingerprint dusting method is one the several methods used by some experts concerning the bite mark investigation. Some researchers have recommended that in addition to customary colour and $\mathrm{B}$ and $\mathrm{W}$ films, ultraviolet photography should be undertaken (Krauss, 1985). The technique consists of irradiating the bite mark with UV light source and exposing a $\mathrm{B}$ and $\mathrm{W}$ film through a UVA filter (Barsley et al., 1990). To preserve the three-dimensional nature of a bite mark, impressions can be taken utilising standard dental impression material which is then poured in dental stone to produce models (Benson et al., 1988). When a suspect is identified, impression can be made in the usual manner to produce dental models and in addition intraoral photographs and bite impressions can be taken. The American Board of Forensic Odontology (1986) first standardised the analysis of bite marks though it was not accepted in the beginning. Further analysis of bite marks is done by superimposition of marked transparency of inked edges of the plaster model of teeth over the bite mark (Humble, 1933).

\section{CONCLUSION}

Human bites tend to occur on the face with relatively high frequency, second only to that of human bites of the upper extremity. These injuries are commonly associated 
with aggressive behaviour, most often involving prominent locations of the face such as ears, nose and lips (Stavrianos et al., 2011b). Indeed, using the teeth to inflict serious injury on an attacker may be the only available defensive method for a victim. Bite marks also have a significant evidential value and important information can be extracted by DNA examination of the collected saliva from the wound scaled photographs and impressions (Sweet and Pretty, 2001). Dental professionals have a major role to play in keeping accurate dental records and providing all necessary information so that legal authorities may recognize malpractice, negligence, fraud or abuse and identify unknown humans (Stavrianos and Vasiliadis, 2002; Avon, 2004). Especially, the dental expert or forensic odontologist has a crucial role in matching the bite mark impressions on a victim to the tooth structure of suspects. Concluding, dentists are obliged to assist in the collection, storage and diagnosis of bite marks. Official organizations should create a law form in order to inform local dentists and/or general physicians in distinguishing and reporting bite marks properly. Afterwards, specialised experts on forensic odontolgy should analyze further the findings. The typical procedures should always be kept as proposed by A.B.F.O.

\section{REFERENCES}

$\mathrm{ABFO}, 1995$. Guidelines and Standards. In: Manual of Forensic Odontology, Bowers, C.M. and G.L. Beli (Eds.). 3rd Edn., American Society of Forensic Odontology, Colorado Springs, pp: 334-353.

$\mathrm{ABFO}$, 2000. Guidelines and standards: Bitemark Guidelines and Standards. American Board of Forensic Odontology, Colorado Springs.

American Board of Forensic Odontology, 1986. Guidelines for bite mark analysis. J. Am. Dent. Assoc., 112: 383-386.

Avon, L.S., 2004. Forensic odontology: The roles and responsibilities of the dentist. J. Can. Dental Assoc., 70: 453-458.

Barsley, R.E., M.H. West and J.A. Fair, 1990. Forensic photography. Ultraviolet imaging of wounds on skin. Am. J. Forensic Med. Pathol., 11: 300-308.

Bell, K., 2000. Identification and documentation of bite marks. J. Emerg. Nurs., 26: 628-630.

Benson, B.W., J.A. Cottone, T.J. Bomberg and N.D. Sperber, 1988. Bite mark impressions: A review of techniques and materials. J. Forensic Sci., 33: $1238-1243$.

Bowers, C.M., 2006. Problem-based analysis of bitemark misidentifications: The role of DNA. Forensic Sci. Int., 1: S104-S109.
Cottone, J.A. and S.M. Standish, 1982. Outline of Forensic Dentistry. Year Book Medical Publishers, Chicago.

David, T.J., 1986. Adjunctive use of scanning electron microscopy in bite mark analysis: A threedimensional study. J. Forensic. Sci., 31: 1126-1134.

De Vore, D.T., 1971. Bite marks for identification. Med. Sci. Law, 11: 144-145.

Dorion, B.J.R., 2005. Bite Mark Evidence. Marcel Dekker, New York.

Herschaft, E., M. Alder, D. Ord, R. Rawson and E. Smith, 2006. Manual of Forensic Odontology. ASFO, Impress Printing and Graphics Inc., New York, pp: $210-240$.

Humble, B.E., 1933. Identification by mean of teeth. Br. Dent. J., 54: 528-528.

Hyzer, W.G. and T.C. Krauss, 1988. The bite mark standard reference scale-ABFO No. 2. J. Forensic Sci., 33: 498-506.

Johnson, L.T. and D. Cadle, 1989. Bite mark evidence. Recognition, preservation, analysis and courtroom presentation. New York State Dent. J., 55: 38-41.

Jones, D.G., 1998. Odontology often is final piece to grim puzzle. J. California Dental Assoc., 26: 650-651.

Kraus, T.C., 1984. Photographic techniques of concern in metric bite mark analysis. J. Forensic Sci., 29: 633-638.

Krauss, T.C., 1985. Forensic evidence documentation using reflective ultraviolet photography. Photo Electronic Imag., 12: 18-23.

McKenna, C.J., M.I. Haron and J.A. Taylor, 1999. Evaluation of a bite mask using clear acrylic replicas of the suspects dentition: A case report. J. Forensic Odontostomatol., 17: 40-43.

Nambiar, P., T.E. Bridges and K.A. Brown, 1995. Quantitative forensic evaluation of bite marks with the aid of a shape analysis computer program: Part 2; SCIP and bite marks in skin and foodstuffs. J. Forensic Odontostomatol., 13: 26-32.

Pretty, I.A. and D. Sweet, 2001. The scientific bases for human bite mark analysis-a critical review. Sci. Justice, 41: 85-92.

Pretty, I.A., 2000. Bitemark overlays: An analysis of effectiveness. Masters Thesis, University of British Columbia, Vancouver.

Pretty, I.A., 2006. The barriers to achieving an evidence base for bitemark analysis. Int. Forensic Sci., 159: S1 10-S120.

Rawson, R.D., A. Bell, B.S. Kinard and J.G. Kinard, 1979. Radiographic interpretation of contrast-mediaenhanced bite marks. J. Forensic. Sci., 24: 898-901.

Rothwell, B.R., 1994. Bitemarks in Forensic Odontology: Fact or Fiction. In: Controversies in Oral and Maxillofacial Surgery, Worthington, P. and J.R. Evans (Ed.). WB Saunders Co., Philadelphia, pp: 588-600. 
Rothwell, B.R., 1995. Bitemarks in forensic dentistry: A review of legal and scientific issues. J. Am. Dental Assoc., 126: 223-232.

Shoemaker, J.S., I.S. Painter and B.S. Weir, 1999. Bayesian statistics in genetics: A guide for the uninitiated. Trends Genet., 15: 354-358.

Sperber, N.D. and H. Lubin, 1981. Bite mark evidence in crimes against persons. J. Am. Coll. Health Assoc., 29: $165-167$.

Stavrianos, C. and L. Vasiliadis, 2002. Forensic Odontology. Investigation of Injuries and Bite Marks. Computer I/O Press, Thessaloniki.

Stavrianos, C., L. Vasiliadis, C. Gogos, E.M. Metska and N. Petalotis, 2003. In vitro evaluation of a computerassisted overlay production technique. Hellenic Dental J., 13: 9-13.

Stavrianos, C., L. Vasiliadis, C. Papadopoulos, A. Kokkas, D. Tatsis, E. Samara 2011a. Loss of the Ear Cartilage from a Human Bite Res. J. Med. Sci., 5: 20-24.

Stavrianos, C., L. Vasiliadis, J. Emmanouil, C. Papadopoulos 2011b. In vivo evaluation of the accuracy of two methods for the bite mark analysis in foodstuff. Res. J. Med. Sci., 5: 25-31.

Stefanopoulos, P.K. and A.D. Tarantzopoulou, 2005. Facial bite wounds: Management update. Int. J. Oral Maxillofacial Surg., 34: 464-472.

Sweet, D. and C.M. Bowers, 1998. Accuracy of bite mark overlays: A comparison of five common methods to produce exemplars from a suspects dentition. J. Forensic. Sci., 43: 362-367.

Sweet, D. and G.G. Shutler, 1999. Analysis of salivary DNA evidence from a bite mark on a body submerged in water. J. Forensic Sci., 44: 1069-1072.
Sweet, D. and I.A. Pretty, 2001. A look at forensic dentistry-Part 2: Teeth as weapons of violenceidentification of bitemark perpetrators. Br. Dent. J., 190: 415-418.

Sweet, D., J.A. Lorente, A. Valenzuela, M. Lorente and E. Villanueva, 1997b. PCR-based DNA typing of saliva stains recovered from human skin. J. Forensic Sci., 42: 447-451.

Sweet, D., M. Lorente, J.A. Lorente, A. Valenzuela and E. Villanueva, 1997a. An improved method to recover saliva from human skin: The double swab technique. J. Forensic Sci., 42: 320-322.

Sweet, D., M. Parhar and R.E. Wood, 1998. Computerbased production of bite mark comparison overlays. J. Forensic Sci., 43: 1050-1055.

Sweet, D.J. and H.A. LeRoy, 1996. Human bitemarksrecovery of forensic evidence from suspects. RCMP Gazette, 58: 2-7.

Sweet, D.J., 1995. Human Bitemarks: Examination, Recovery and Analysis. In: Manual of Forensic Odontology, Bowers C.M. and G.L. Bell (Eds.). American Society of Forensic Odontology, Colorado Springs, pp: 148-170.

Vale, G.L. and T.T. Noguchi, 1983. Anatomical distribution of human bitemarks in a series of 67 cases. J. Forensic Sci., 28: 61-69.

Webb, D.A., I.A. Pretty and D. Sweet, 2000. Bitemarks: A psychological approach. Proc. Am. Acad. Forensic Sci., 6: 147-147.

Wright, D.F. and S.G. Golden, 1997. Forensic Photography. In: Forensic Dentistry, Stimson, G.P. and A.C. Mertz (Eds.). CRC Press, Boca Raton, FL. USA., pp: 105-106. 